\title{
Comparative analysis of safety and efficacy of photorefractive keratectomy versus photorefractive keratectomy combined with crosslinking
}

This article was published in the following Dove Press journal:

Clinical Ophthalmology

\author{
Gitansha Shreyas Sachdev \\ Shreyas Ramamurthy \\ Ramamurthy Dandapani \\ Refractive Services, The Eye \\ Foundation, Coimbatore, India
}

\begin{abstract}
Purpose: To assess the safety, efficacy, and refractive predictability of half-fluence accelerated corneal collagen crosslinking (CXL) applied concurrently with photorefractive keratectomy (PRK), and compare the results to standard PRK.
\end{abstract}

Setting: Refractive Services, The Eye Foundation, Coimbatore, India.

Design: Interventional comparative case series.

Methods: Patients seeking refractive correction for myopia or myopic astigmatism were included in the study. Photorefractive keratectomy with concurrent half-fluence crosslinking (PRK Xtra) was performed in eyes with borderline suspicious tomography (not amounting to forme fruste keratoconus) or low pachymetry between 450 and $474 \mu \mathrm{m}$ with an otherwise unremarkable corneal tomography. Eyes with normal corneal tomography and thickness between 475 and $500 \mu \mathrm{m}$ underwent standard PRK. The minimum follow-up period was 1 year.

Results: In total, 109 eyes underwent PRK Xtra (Group A) and 118 eyes underwent PRK alone (Group B). The preoperative MRSE was $-3.64 \mathrm{D}$ and $-3.38 \mathrm{D}$ in Groups A and B, respectively $(P=0.28)$. Group A had a significantly higher number of eyes with thinner corneas $(P<0.01)$ and corneal tomographic abnormalities $(P=0.02)$. At 1 year follow-up, $96.3 \%$ of eyes in group A as against $99.1 \%$ of eyes in group B achieved a best corrected distance visual acuity (CDVA) of $20 / 20$ or better. No iatrogenic ectasia or hyperopic shift secondary to progressive flattening was noted in the PRK Xtra group. No significant difference in incidence of haze was noted.

Conclusion: PRK Xtra showed comparable safety, efficacy, and stability to PRK in eyes with thinner pachymetry and tomographic abnormalities. Combining crosslinking with PRK in suspicious tomographies augurs for safe and predictable outcomes.

Keywords: photorefractive keratectomy, PRK, corneal collagen crosslinking, CXL, PRK Xtra

\section{Introduction}

Iatrogenic keratectasia and myopic regression are well recognized complications following keratoablative procedures, both of which occur in part due to biomechanical weakening of the cornea. ${ }^{1}$ Corneal ectasia presents as increasing myopia and astigmatism, due to progressive corneal steepening that occurs centrally or inferiorly. ${ }^{2}$ A younger age group, lower residual corneal thickness, and high refractive errors are recognized as risk factors. Corneal collagen crosslinking (CXL) enhances corneal rigidity and reduces the possibility of long term myopic shift. ${ }^{3}$ Prophylactic CXL has been applied concurrently with laser in situ keratomileusis (LASIK) to reduce the incidence of regression and possible ectasia. ${ }^{4-6}$ 
This study aims to investigate the potential differences in safety, efficacy, and refractive predictability of Photorefractive keratectomy (PRK) alone versus PRK with concurrent half fluence CXL in eyes with borderline corneal pachymetry or tomography.

\section{Patients and methods}

The study was an interventional comparative case series conducted on patients who presented to Refractive Services between January 2013 and August 2015. The study adhered to the tenets of the Declaration of Helsinki, and an approval was obtained from the Ethics Committee of our hospital (Ethics Committee of The Eye Foundation, Coimbatore). A written informed consent was obtained from all the patients enrolled in this study.

Patients seeking refractive correction for myopia or myopic astigmatism were included in the study. Primary inclusion criteria were age greater than 18 years, a stable refractive error (change in spherical equivalent of not more than $0.25 \mathrm{D}$ ) for at least 1 year, and discontinuation of contact lenses for a minimum duration of 2 weeks. Patients with a corrected distance visual acuity (CDVA) of 20/25 or better and a spherical equivalent refraction of up to $-6.0 \mathrm{D}$ were included in the study. Exclusion criteria included post ablation corneal thickness of less than $400 \mu \mathrm{m}$, topographic evidence of corneal ectasia, previous ocular surgery, history of herpetic eye disease, corneal scarring, collagen vascular disease, pregnancy, and lactation.

All patients underwent a detailed anterior and posterior segment evaluation to rule out ocular comorbidities. Corneal tomography was performed using the Oculus Pentacam Scheimpflug Imaging. Patients with a corneal pachymetry between 475 and $500 \mu \mathrm{m}$ and normal corneal tomography were considered suitable candidates for PRK alone. Patients with corneal pachymetry between 450 and $474 \mu \mathrm{m}$ and a normal tomography (Figure 1) or those exhibiting subtle tomographic abnormalities (mild inferior-superior asymmetry or overall D red) not amounting to forme-fruste or subclinical keratoconus (Figure 2A and B) underwent PRK with concurrent half fluence CXL.

\section{Surgical technique}

Following instillation of proparacaine hydrochloride drops $1 \%$, a wire lid speculum was placed. In all eyes, the excimer

\section{Wavelight - allegro oculyzer 4 maps refractive}

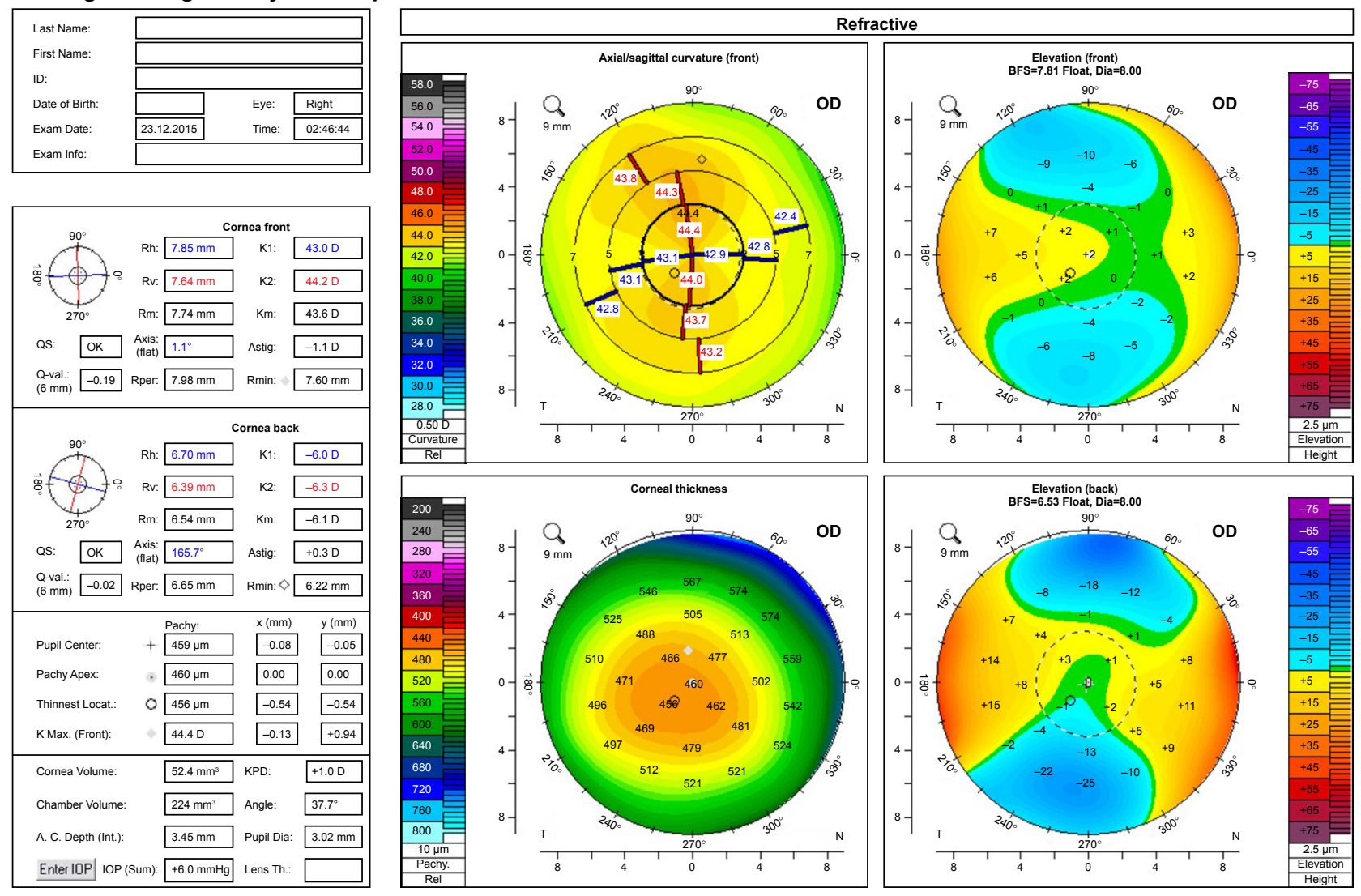

Figure I Preoperative corneal tomography of a patient seeking refractive correction for $-2.50 \mathrm{D}$. Corneal tomography demonstrates a reduced pachymetry with no other abnormalities. The patient underwent PRK combined with CXL.

Abbreviations: CXL, corneal collagen crosslinking; OD, oculus dexter [right eye]; PRK, photorefractive keratectomy. 
A

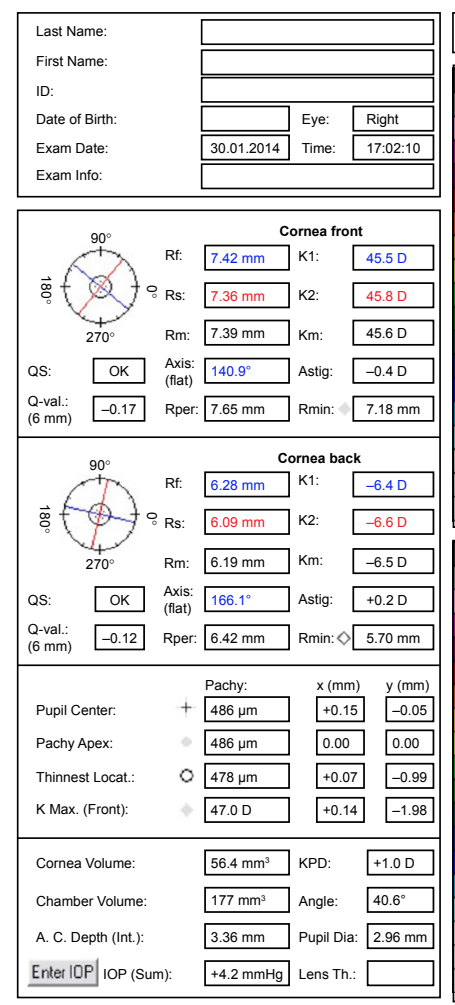
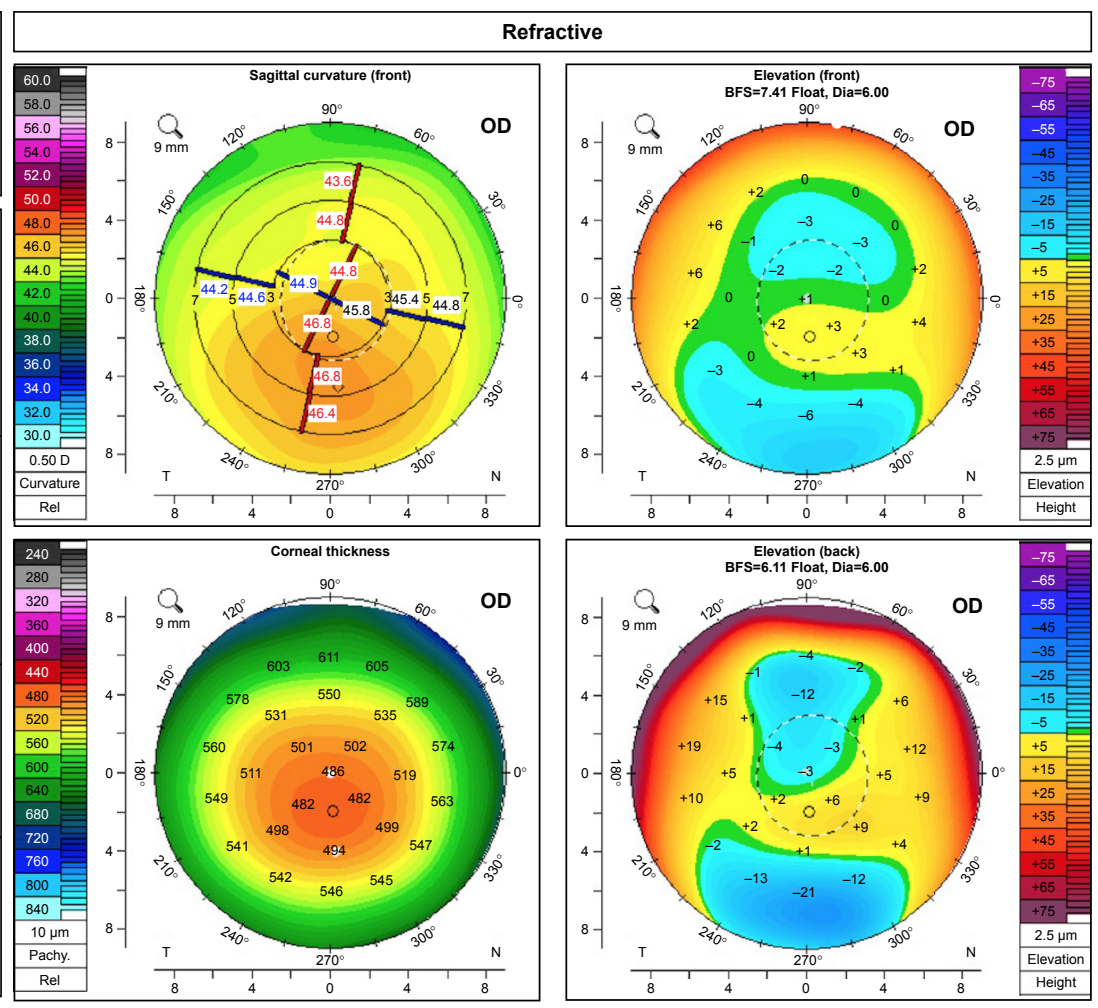

B

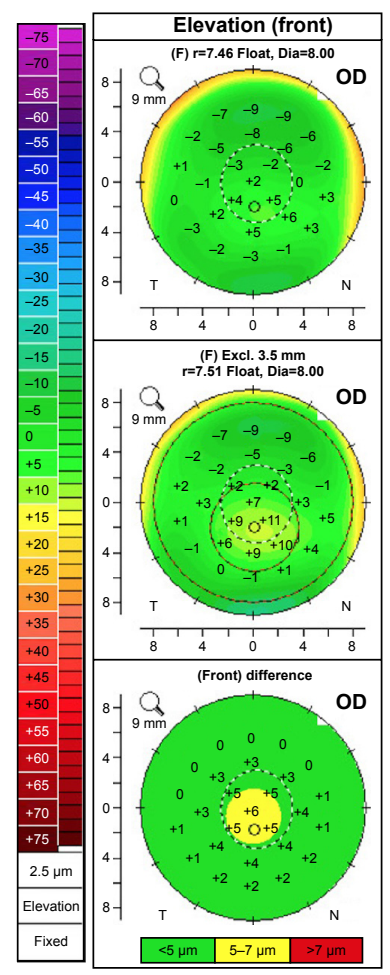

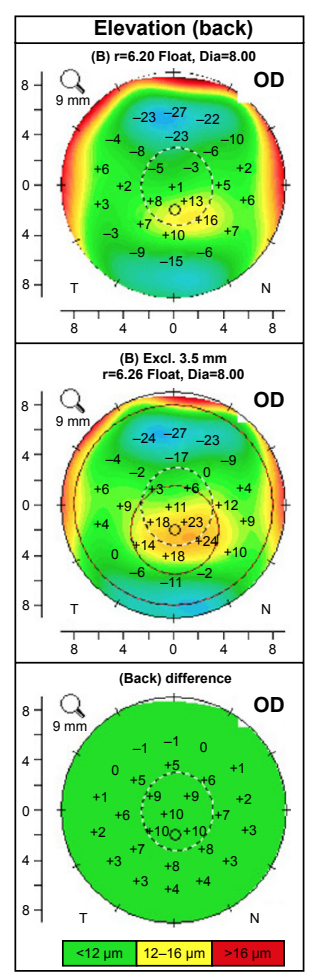

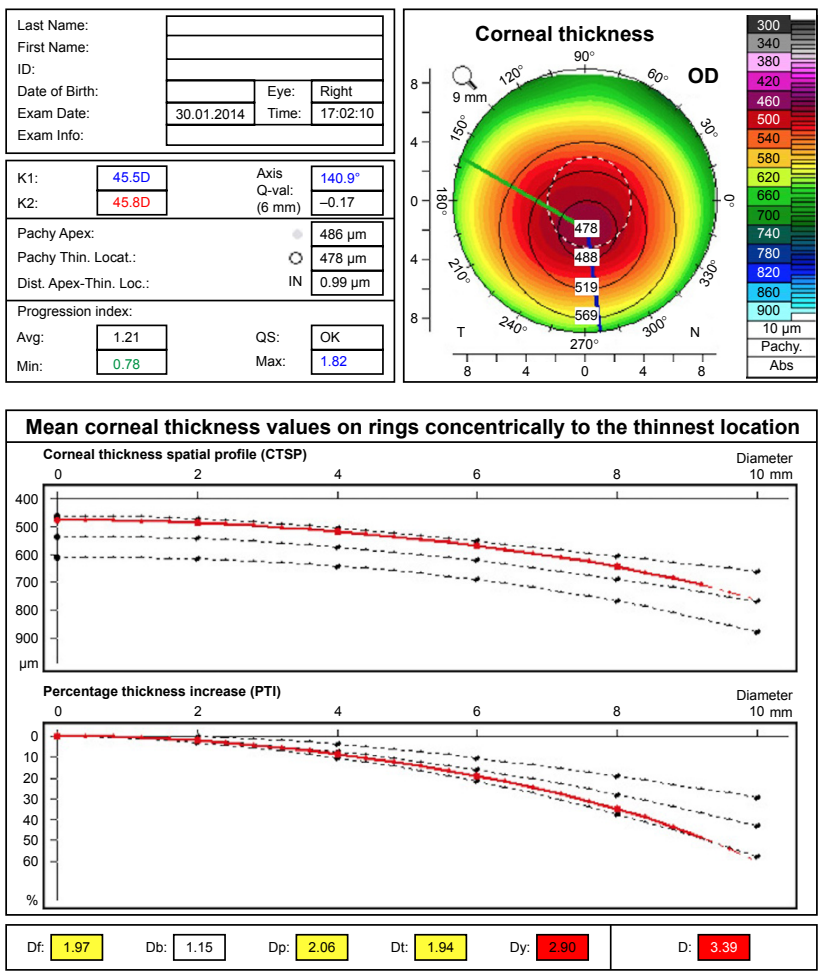

Figure 2 Preoperative corneal tomography of a patient seeking refractive correction; $-3.50 \mathrm{D}$. Corneal tomography demonstrates an inferior superior asymmetry $(\mathbf{A})$ with an overall $D$ of red $(\mathbf{B})$.

Abbreviation: OD, oculus dexter [right eye].

laser ablation was performed using the Wavelight Allegretto EX 500 system (Alcon Laboratories, Fort Worth, TX, USA). The epithelial removal was carried out using the phototherapeutic keratectomy mode at a pre-set depth of $50 \mu \mathrm{m}$. This was followed by myopic ablation treatment with a $6.00 \mathrm{~mm}$ treatment zone diameter and a transition zone of $1.25 \mathrm{~mm}$. No adjustment in the excimer ablation nomogram was done for the PRK Xtra group. 
Subsequent to the excimer laser treatment, mitomycin $\mathrm{C}$ (MMC) $0.02 \%$ was applied for $30 \mathrm{~s}$ in the PRK only group. The ocular surface was then washed thoroughly with normal saline solution, and a bandage contact lens was placed.

In patients undergoing concurrent CXL, 0.25\% riboflavin drops (VibeX Xtra, Avedro, Waltham, MA, USA) were instilled over the exposed stroma and spread carefully over the stromal bed for the next $90 \mathrm{~s}$. The riboflavin drops were applied immediately following ablation. Following the riboflavin soak, the excessive drops were irrigated and a half fluence UVA (ultraviolet A) irradiation at $30 \mathrm{~mW} / \mathrm{cm}^{2}$ was applied for $90 \mathrm{~s}$ (energy dose of $2.7 \mathrm{~J} / \mathrm{cm}^{2}$ ) using the KXL accelerated crosslinking device (Avedro Inc, Waltham, MA, USA). No further drops of riboflavin were administered during the UVA irradiation. A bandage contact lens was placed at the end of the procedure.

The postoperative protocol for both groups included loteprednol etabonate $0.5 \%$ topical suspension in tapering dose for 6 weeks, moxifloxacin hydrochloride eye drops $0.5 \%$ four times per day for a week, and polyethylene glycol and propylene glycol ophthalmic solution six times per day for 2 months.

\section{Postoperative examination}

Postoperative visits included postoperative day 1 , day 5 , 6 weeks, 3 months, 6 months, and 1 year. The bandage contact lens was removed on the fifth postoperative day following epithelium healing. Binocular and monocular uncorrected and best corrected visual acuity were recorded for both distance and near. Contrast sensitivity (Pelli-Robson contrast sensitivity test) was measured for both mesopic and photopic conditions. The secondary outcome measurements included incidence and resolution of corneal haze and incidence of residual error or regression. ${ }^{7}$ Endothelial cell loss was measured using specular microscopy (Topcon SP). An anterior segment OCT (Avanti; Optovue Inc, Fremont, CA, USA) was used to measure the depth of the demarcation line in the PRK Xtra group at 1-month postoperative visit.

\section{Statistical analysis}

The type of refractive procedure (PRK Xtra vs PRK) was considered as the primary explanatory variable. Various visual outcome related parameters in the postoperative period were considered as outcome variables. Age, gender, and baseline visual parameters were considered as potential confounders.

All the quantitative variables were assessed for compliance with normal distribution within each treatment group by visual inspection of histograms, Normality Q-Q plots, and also by assessing the $P$-values of the Shapiro-Wilk test and Kolmogorov-Smirnov test.

All normally distributed quantitative variables were compared across the two groups by median and standard deviations using the Independent sample $t$-test to assess statistical significance. All the categorical variables were compared across the groups by crosstabulation and comparison of proportions using the chi-square test. $P$-value $<0.05$ was considered statistically significant.

\section{Results}

Patient demographics and characteristics are represented in Table 1. Of the 109 eyes belonging to group A (PRK Xtra), 52 patients underwent bilateral treatments and five were unilateral. The mean age in this group was $24.19 \pm 3.54$ years. The preoperative mean refractive spherical equivalent (MRSE) was $-3.64 \pm 1.44 \mathrm{D}$ and the mean refractive error was $-3.20 \pm 1.51 \mathrm{D}$ sphere with $-0.89 \pm 0.65 \mathrm{D}$ cylinder.

The second group (PRK alone) included 118 eyes. Of these, 56 patients underwent bilateral treatment and six were unilateral. The mean age was $25.92 \pm 4.91$ years. The preoperative mean spherical refractive equivalent (MRSE) was $-3.38 \pm 1.65 \mathrm{D}$ and the mean refractive error was $-3.09 \pm 1.44 \mathrm{D}$ sphere with $-1.05 \pm 0.94 \mathrm{D}$ cylinder.

The mean preoperative central corneal thickness was 477.7 $\pm 19.31 \mu \mathrm{m}$ and 479.7 $\pm 29.37 \mu \mathrm{m}$ in Groups A and B, respectively $(P=0.556)$. However, notably 58 eyes in the PRK Xtra group had a preoperative pachymetry between 450-474 $\mu \mathrm{m}$ as compared to none in the PRK group $(P<0.01)$. Of the remaining 51 eyes in the PRK Xtra group, all of them had tomographic abnormalities with Overall D being yellow in 23 eyes and red in 28 eyes $(P=0.02)$.

Table I Demographics and patient characteristics

\begin{tabular}{|c|c|c|c|}
\hline $\begin{array}{l}\text { Demographics and } \\
\text { characteristics }\end{array}$ & $\begin{array}{l}\text { Group A } \\
\text { (PRK-CXL): } \\
\text { I } 09 \text { eyes }\end{array}$ & $\begin{array}{l}\text { Group B } \\
\text { (PRK alone): } \\
\text { I } 18 \text { eyes }\end{array}$ & $P$-value \\
\hline Age (years) & $24.19 \pm 3.542$ & $25.92 \pm 4.906$ & 0.003 \\
\hline $\begin{array}{l}\text { Male:female ratio } \\
\text { Preoperative MRSE (D) }\end{array}$ & $\begin{array}{l}0.75: 1 \\
-3.64 \pm 1.436\end{array}$ & $\begin{array}{l}0.53: 1 \\
-3.38 \pm 1.647\end{array}$ & $\begin{array}{l}0.195 \\
0.28\end{array}$ \\
\hline Postoperative MRSE (D) & $-0.04 \pm 0.197$ & $-0.01 \pm 0.102$ & 0.153 \\
\hline Preoperative CCT $(\mu \mathrm{m})$ & $477.7 \pm 19.31$ & $479.7 \pm 29.37$ & 0.556 \\
\hline Postoperative CCT $(\mu \mathrm{m})$ & $417.4 \pm 30.12$ & $427.2 \pm 21.15$ & 0.021 \\
\hline $\begin{array}{l}\text { Preoperative endothelial cell } \\
\text { count (cells } / \mathrm{mm}^{2} \text { ) }\end{array}$ & $2,5 \mid 4.3 \pm 180.7$ & $2,602 \pm 201.1$ & 0.72 \\
\hline $\begin{array}{l}\text { Postoperative endothelial cell } \\
\left.\text { count (cells } / \mathrm{mm}^{2}\right)\end{array}$ & $2,497 \pm 168.3$ & $2,591.4 \pm 187.2$ & 0.69 \\
\hline
\end{tabular}

Abbreviations: $\mathrm{CCT}$, central corneal thickness; CXL, corneal collagen crosslinking; MRSE, mean refractive spherical equivalent; PRK, photorefractive keratectomy. 


\section{Postoperative uncorrected and best corrected visual acuity}

Postoperatively an uncorrected visual acuity of 20/20 or better was achieved in 101 eyes (92.67\%) in Group A and in 113 eyes (95.75\%) in Group B. This difference was not statistically significant $(P=0.14)$.

A best corrected visual acuity of $20 / 20$ or better was achieved in 105 eyes (96.33\%) and 117 eyes (99.1\%) in groups $\mathrm{A}$ and $\mathrm{B}$, respectively $(P=0.23)$. Contrast sensitivity was measured both in photopic and mesopic conditions. Intra and intergroup comparison of preoperative and postoperative measurements did not reveal any significant difference between the two groups.

\section{Refractive predictability and accuracy}

A refractive predictability within $0.50 \mathrm{D}$ was achieved in $95.4 \%$ and $97.4 \%$ of the eyes in groups $\mathrm{A}$ and $\mathrm{B}$, respectively $(P=0.8)$. Nine eyes in Group A had a residual error ranging from $-0.25 \mathrm{D}$ to $-1.25 \mathrm{D}$, with a mean residual error of -0.59 D. Six eyes in group B had a residual error ranging from $-0.25 \mathrm{D}$ to $-1.25 \mathrm{D}$, with a mean residual error of -0.60 D.s

\section{Gain or loss of lines}

The gain-loss data (preoperative CDVA versus postoperative CDVA) (Figure 3) indicates that, in group A, 90 eyes $(82.56 \%)$ had unchanged CDVA, while one eye $(0.91 \%)$ lost one line, 17 eyes (15.59\%) gained one line, and one eye $(0.91 \%)$ gained two lines in CDVA.
In group B, 103 eyes (87.29\%) had no change, while 15 eyes $(12.7 \%)$ gained one line in CDVA.

\section{Refractive and keratometric stability}

Refractive stability was demonstrated by the MRSE correction, as followed during the 6 weeks, 3 and 12 months' postoperative visits (Figure 4). The 1 year mean postoperative MRSE was $-0.04 \pm 0.19 \mathrm{D}$ and $-0.01 \pm 0.10 \mathrm{D}$ in groups $\mathrm{A}$ and $\mathrm{B}$, respectively $(P=0.153)$. None of the eyes in the PRK Xtra group noted overcorrection or hyperopic shift.

Keratometric changes in both groups were similar over a 1 year follow-up period (Figure 5). A mean keratometric value of $41.74 \pm 2.17 \mathrm{D}$ and $41.63 \pm 1.72 \mathrm{D}$ at 1 year was seen in groups $\mathrm{A}$ and $\mathrm{B}$, respectively $(P=0.723)$. No progressive flattening or refractive shift was noted in either group.

\section{Demarcation line}

A patchy demarcation line was noted at a depth of $180.3 \pm 21.6 \mu \mathrm{m}$ at 1 -month postoperative visit in the PRK Xtra group.

\section{Complications and adverse effects}

No adverse effects like diffuse lamellar keratitis (DLK) or infections were reported in either groups. In the PRK Xtra group, nine eyes developed grade 1 superficial corneal haze, which resolved by the 6 month follow-up visit. It was of note that all these patients had a preoperative MRSE of greater than $-3.0 \mathrm{D}$, with a mean of $-4.4 \mathrm{D}$. Endothelial cell counts at preoperative and 1-month postoperative visit showed no statistically significant difference in both groups. No cases of postoperative ectasia were noted in either group, up to

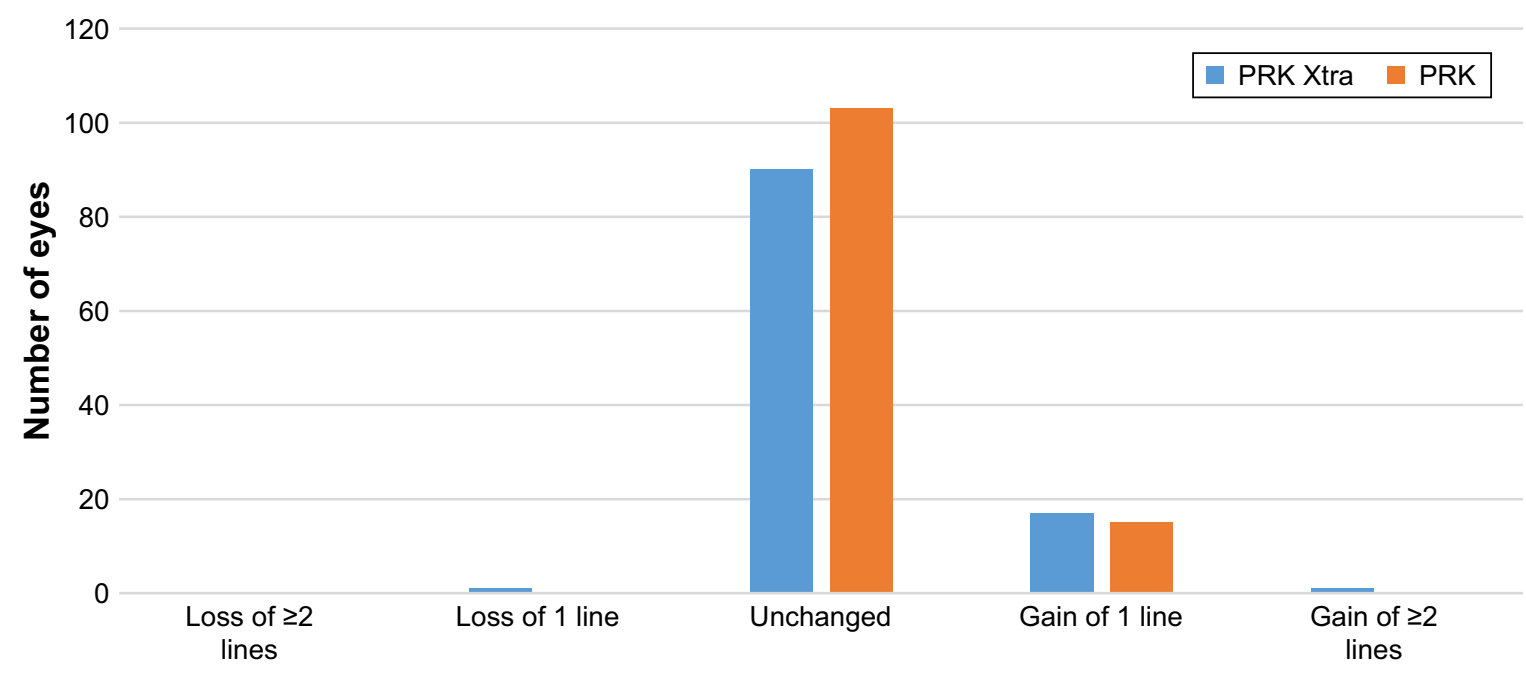

Figure 3 Change in corrected visual acuity, as number of eyes with gain/loss in Snellen lines of corrected distance visual acuity I-year postoperatively. Abbreviation: PRK, photorefractive keratectomy. 


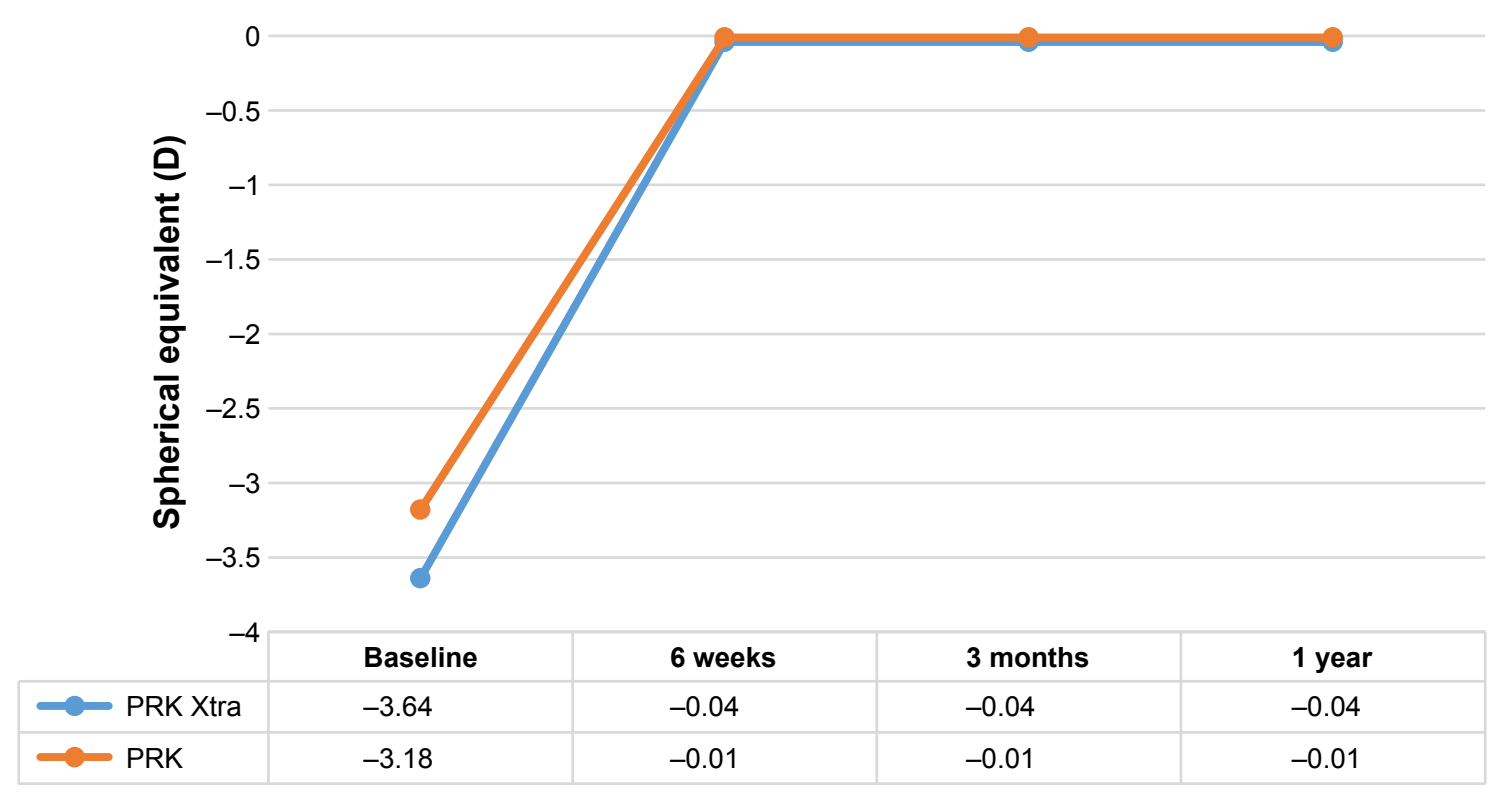

Figure 4 Refractive stability in both groups during I year follow-up.

Abbreviation: PRK, photorefractive keratectomy.

the last follow-up visit, with a mean follow-up of 28.4 months.

\section{Discussion}

Keratorefractive surgeries reduce the biomechanical strength of the cornea, both due to flap creation and stromal ablation. ${ }^{1}$ The role of crosslinking to halt the progression of keratoconus by increasing the corneal rigidity has been well established. ${ }^{3}$ The safety and efficacy of combining a partial surface ablation with crosslinking in keratoconic eyes has been described..$^{8-10}$ Recently crosslinking has been combined with laser vision correction in eyes with high refractive errors, to reduce the incidence of regression. ${ }^{4,11,12}$

In our study, patients with lower corneal pachymetry (between 450 and $474 \mu \mathrm{m}$ ) or those exhibiting subtle tomographic abnormalities (mild inferior-superior asymmetry or overall D red, not amounting to forme fruste or subclinical keratoconus) underwent PRK with half-fluence CXL.

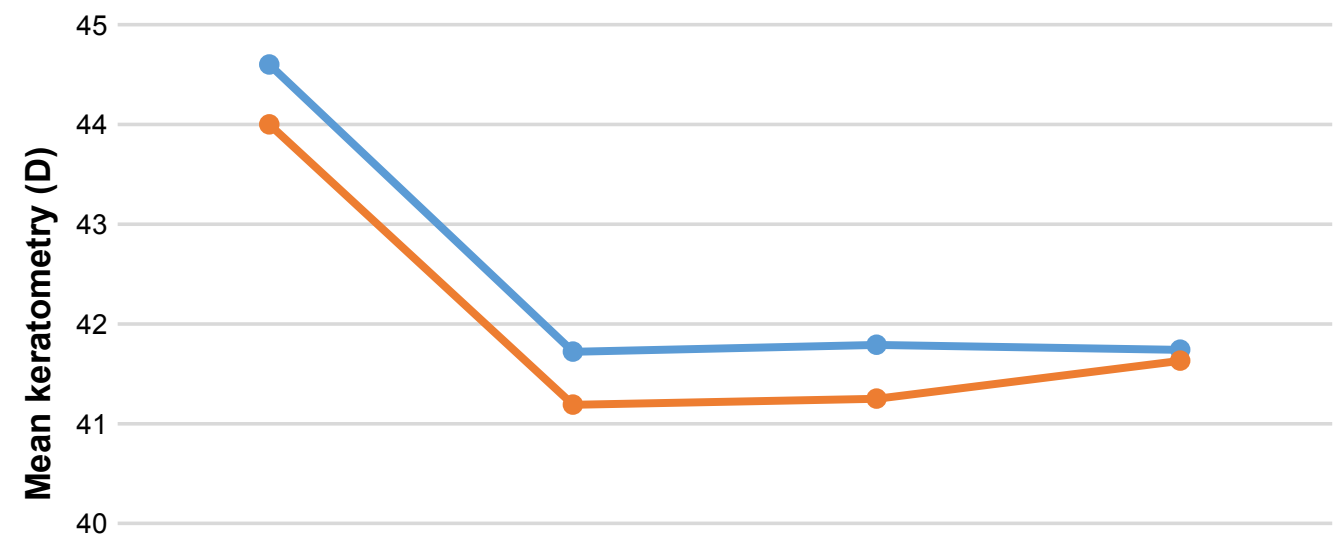

\begin{tabular}{|l|l|l|l|l|}
\multicolumn{1}{c|}{39} & Baseline & Postoperative & 3 months & 1 year \\
\hline & 44.6 & 41.72 & 41.79 & 41.74 \\
\hline- PRK Xtra & 44 & 41.19 & 41.25 & 41.63 \\
\hline
\end{tabular}

Figure 5 Keratometric stability in both groups during I year follow-up. Abbreviation: PRK, photorefractive keratectomy. 
The concept behind applying concurrent CXL in these eyes was to compensate for the biomechanical weakness induced by the excimer ablation and to reduce the risk of ectasia and regression in these borderline corneas.

Progressive corneal flattening leading to overcorrection or visual loss following haze were some of the concerns behind combining CXL with laser vision correction. The advent of accelerated crosslinking methods enables us to achieve similar biomechanical stability as conventional treatment, without the induction of excessive corneal flattening. ${ }^{13}$ In our study, we used accelerated crosslinking with a high irradiance of $30 \mathrm{~mW} / \mathrm{cm}^{2}$ for a period of $90 \mathrm{~s}$, delivering a total fluence of $2.7 \mathrm{~J} / \mathrm{cm}^{2}$. This protocol has been used previously along with LASIK in eyes undergoing correction for high myopia and hyperopia. ${ }^{4,6}$ No correction or adjustment was made in the excimer laser algorithm for the PRK Xtra group. Similar studies combining laser in situ keratomileusis with CXL for myopic and hyperopic correction did not apply any corrections in the ablation algorithm. ${ }^{4-6}$ No overcorrection was noted in any of the eyes of the PRK Xtra group at 1 year follow-up. Hence, concurrent crosslinking in low dosage does not require undercorrection or adjustments in the excimer laser ablation nomogram.

MMC was not applied following laser ablation in the PRK Xtra group. A lower incidence of haze was expected due to crosslinking induced keratocyte apoptosis in the anterior corneal stroma. Nine eyes, however, developed postoperative grade 1 haze as against no eyes in the PRK only group. The haze, however, subsided within the first 6 months, and all eyes achieved a CDVA of 20/20. It is noteworthy that all patients presenting with haze received a refractive correction of greater than $-3.0 \mathrm{D}$. Although the minimal haze did not affect the visual outcome in our series, we recommend the use of $0.02 \%$ MMC. Even when the laser correction is being combined with crosslinking in this accelerated half fluence mode, it is likely that the amount of apoptosis caused by this form of crosslinking may not be sufficient to prevent haze formation.

\section{Conclusion}

Our study was able to establish the safety and refractive efficacy of combining crosslinking with standard PRK in eyes with borderline corneal pachymetry and in eyes with subtle abnormalities on corneal tomography. Concurrent crosslinking in such corneas could help maintain biomechanical stability following excimer ablation. Long-term results are awaited to establish the superiority of this protocol.

\section{What was known}

Iatrogenic keratectasia and myopic regression are well recognized complications of keratoablative procedures, and CXL, when combined with LASIK, enhances corneal rigidity and reduces the possibility of long-term myopic shift.

\section{What this paper adds}

Combining half fluence crosslinking with standard surface ablation augurs for excellent refractive results in thin corneas and borderline corneal tomography, and no progressive flattening or hyperopic shift is seen, thereby maintaining the safety and efficacy of the refractive procedure.

\section{Disclosure}

The authors report no conflicts of interest in this work.

\section{References}

1. Randleman JB. Post-laser in-situ keratomileusis ectasia: current understanding and future directions. Curr Opin Ophthalmol. 2006;17: 406-412.

2. Binder PS. Analysis of ectasia after laser in situ keratomileusis: risk factors. J Cataract Refract Surg. 2007;33:1530-1538.

3. Randleman JB, Khandelwal S, Hafezi F. Corneal cross-linking. Surv Ophthalmol. 2015;60:509-523.

4. Tamayo GE. Predictable visual outcomes with accelerated corneal cross-linking concurrent with laser in situ keratomileusis. $J$ Cataract Refract Surg. 2012;38(12):2206-2208.

5. Aslanides IM, Mukherjee AN. Adjuvant corneal crosslinking to prevent hyperopic LASIK regression. Clin Ophthalmol. 2013;7:637-641.

6. Celik HU, Alagöz N, Yildirim Y, et al. Accelerated corneal crosslinking concurrent with laser in situ keratomileusis. J Cataract Refract Surg. 2012;38(8):1424-1431.

7. Nakamura K, Kurosaka D, Bissen-Miyajima H, Tsubota K. Intact corneal epithelium is essential for the prevention of stromal haze after laser assisted in situ keratomileusis. Br J Ophthalmol. 2001;85:209-213.

8. Kanellopoulos AJ, Asimellis G. Keratoconus management: long-term stability of topography-guided normalization combined with highfluence CXL stabilization (the Athens protocol). J Refract Surg. 2014; 30:88-93.

9. Kymionis GD, Kontadakis GA, Kounis GA, et al. Simultaneous topography-guided PRK followed by corneal collagen cross-linking for keratoconus. J Refract Surg. 2009;25:S807-S811.

10. Kanellopoulos AJ. Comparison of sequential vs same-day simultaneous collagen cross-linking and topography-guided PRK for treatment of keratoconus. J Refract Surg. 2009;25:S812-S818.

11. Tomita M, Yoshida Y, Yamamoto Y, Mita M, Waring G. In vivo confocal laser microscopy of morphologic changes after simultaneous LASIK and accelerated collagen crosslinking for myopia: one-year results. $J$ Cataract Refract Surg. 2014;40:981-990.

12. Kanellopoulos AJ, Asimellis G, Karabatsas C. Comparison of prophylactic higher fluence corneal cross-linking to control in myopic LASIK: one year results. Clin Ophthalmol. 2014;8:2373-2381.

13. Shetty R, Pahuja N, Nuijts RM, et al. Current protocols of corneal collagen cross-linking: visual, refractive, and tomographic outcomes. Am J Ophthalmol. 2015;160(2):243-249. 


\section{Publish your work in this journal}

Clinical Ophthalmology is an international, peer-reviewed journal covering all subspecialties within ophthalmology. Key topics include: Optometry; Visual science; Pharmacology and drug therapy in eye diseases; Basic Sciences; Primary and Secondary eye care; Patient Safety and Quality of Care Improvements. This journal is indexed on

Submit your manuscript here: http://www.dovepress.com/clinical-ophthalmology-journal
PubMed Central and CAS, and is the official journal of The Society of Clinical Ophthalmology (SCO). The manuscript management system is completely online and includes a very quick and fair peer-review system, which is all easy to use. Visit http://www.dovepress.com/ testimonials.php to read real quotes from published authors. 